\title{
A Rússia e os possíveis impactos da pandemia COVID-19
}

Russia and the possible impacts of the COVID-19 pandemic

La Russia y los possibles impactos de la pandemia del COVID-19

Daniela Vieira Secches ${ }^{1}$

Marina Nunes Bernardes ${ }^{2}$

DOI: $10.5752 /$ P.1809-6182.2020v17n3p19

Recebido em: 03 de agosto de 2020 Aceito em: 01 de setembro de 2020

\section{Resumo}

Esse artigo tem o objetivo de identificar os possiveis impactos politicos e econômicos da pandemia do COVID-19 para a Rússia e as respostas do governo Putin a esses desafios. Para que isso seja realizado, é feita uma análise conjuntural do problema sob uma perspectiva descritivo-analitica.

Palavras-chave: COVID-19. Rússia. Análise conjuntural.

\begin{abstract}
This paper aims to identify the possible political and economic impacts of the COVID-19 pandemic to Russia and the Putin's government responses to these challenges. For this to be achieved, the problem's conjunctural analysis is made under a descriptive-analytical perspective. Keywords: COVID-19. Russia. Conjunctural analysis.

\section{Resumen}

Este artículo tiene como objetivo analizar los possibles politicos y económicos de la pandemia del COVID-19 para la Rusia y las respostas del gobierno Putin a estos desafios. Para que eso sea realizado, se hace una análisis coyuntural del problema sob uma perspectiva descriptivo-analitica.

Palabras clave: COVID-19; Rusia. Análisis coyuntural.
\end{abstract}

\footnotetext{
1 Doutora em Relaçôes Internacionais pela Pontifícia Universidade Católica de Minas Gerais, Belo Horizonte - Brasil. ORCID: https://orcid.org/0000-0003-4682-4665.

2 Mestre em Relaçôes Internacionais pela Pontifícia Universidade Católica de Minas Gerais, Belo Horizonte - Brasil. ORCID: https://orcid.org/0000-0001-5261-1354.
} 


\section{Introdução}

$\mathrm{O}$ mundo vive um momento ímpar em sua história. Atravessado pela pandemia de uma enfermidade altamente contagiante e de complexo tratamento - a COVID-19, as relações internacionais testemunham mudanças profundas em suas dinâmicas de interação, e muito se especula sobre a nova normalidade a nascer após findada essa crise sanitária. Apesar de ainda ser cedo para que sejam propostas conjecturas de médio e longo prazo sobre o tema, é de extrema relevância que os estudos sobre política internacional mobilizem reflexôes acerca dos possíveis impactos da pandemia. Diante das incertezas, uma boa estratégia para tanto é acompanhar a reação de atores centrais para o sistema internacional às circunstâncias da crise, e refletir sobre seus impactos.

Com isso em mente, o presente artigo propóe uma análise conjuntural acerca da reaçâo russa à pandemia COVID-19. Para isso, foi realizado um levantamento de dados em fontes primárias, especialmente, e secundárias, em alguns casos, para analisar a reação do governo russo à pandemia. Inicialmente, em uma perspectiva descritivo-analítica, será traçada a evolução da pandemia COVID-19 no país, considerando o quadro geral da saúde na Rússia, os desdobramentos da pandemia ao longo do tempo, e as medidas tomadas pelo governo. Essa discussão será estruturada por temas, ressaltando diferentes pontos relevantes da resposta do governo russo frente a pandemia ao longo de seus primeiros meses no país - fevereiro, março, abril, e maio de 2020. Em seguida, questóes polêmicas sobre a crise sanitária e seus impactos políticos e econômicos para a Rússia no contexto global serão analisados. Nessa seçáo, os métodos utilizados serão a estatística descritiva com base em fontes primárias, a análise de conteúdo de documentos do Executivo russo, e a revisão bibliográfica de fontes secundárias especializadas.

\section{A evolução da pandemia COVID-19 na Rússia}

A evolução da pandemia COVID-19 na Rússia dá-se em um quadro de saúde pública altamente centralizado, que herda o modelo soviético Semashko. ${ }^{3}$ Em 1993, após o fim da União Soviética, o país adotou o seguro de saúde obrigatório e começou a construir um sistema focado no acesso universal ao cuidado básico. Contudo, observa-se fortes diferenças de acesso entre os meios urbano e rural. A despeito do aumento dos investimentos em saúde nos últimos anos, totalizando, atualmente, 7,1\% do Produto Interno Bruto (PIB) do país, a Rússia ocupa a $140^{\circ}$ posição no ranking mundial de investimento na área (OMS, 2020a; ORLOVA, 2020).

Os primeiros casos registrados de contaminação pelo coronavírus no país foram registrados no dia 31 de janeiro de 2020, com a confirmação da infecção de dois cidadãos chineses da Sibéria. Imediatamente, foram tomadas uma série de medidas em fevereiro com especial foco nos estrangeiros, como o banimento da entrada de chineses e iranianos, o autoisolamento e o acompanhamento de pessoas vindas da China, e a diminuição de voos e trens a locais relacionados com alto índice de contaminação. Com o aumento dos casos em março e a declaraçáo da

3 Modelo de assistência médica primária da Rússia e de outros países do espaço pós-soviético. Foi nomeado em homenagem ao Ministro da Saúde da URSS, Nikolai Semashko. Esse modelo garante acesso à saúde pública e melhorou significantemente a vida da população. No entanto, ele sofre duras críticas por contar com um financiamento baixo do governo e por se mostrar ineficiente em diversas regióes (SHEIMAN et al., 2018). 
COVID-19 como pandemia global pela Organização Mundial de Saúde (OMS), decidiu-se pelo acirramento das medidas de banimento de entrada de estrangeiros e pela ampliação do fechamento de fronteiras. Nesse cenário, criou-se um grupo de trabalho especial dentro do Conselho de Estado do Kremlin, a ser comandado pelo prefeito de Moscou, Sergei Sobyanin ${ }^{4}$ (PRESIDENT OF RUSSIA, 2020). Até o dia 19 de março, quando ocorreu a primeira morte oficialmente causada pela COVID-19 na Rússia, o discurso estatal apresentava tom otimista no que diz respeito à capacidade do Estado de conter a crise sanitária. Contudo, a partir do crescimento do número de contaminaçôes e de mortes (Tabela 1 e Gráfico 1), o discurso foi endurecido e declarou-se alerta vermelho nacional, com banimento de aglomeraçóes, instituição de aulas online e incentivo ao home office (PRESIDENT OF RUSSIA, 2020b).

Entre abril e maio de 2020, com a piora considerável no número de contaminados e de óbitos, a gravidade da crise foi crescentemente reconhecida pelo Estado, com o fechamento de todas as atividades não essenciais e a declaração de feriados pagos entre os dias 28 de março e 13 de maio

4 O grupo de trabalho especial para COVID-19 é composto por Sergei Sobyanin (Prefeito de Moscou); Andrei Belusov (Primeiro Vice-Primeiro Ministro); Tatyana Golikova (Vice de Andrei Belusov); Dmitry Chernyshenko (Vice de Andrei Belusov); Mikhail Murashko (Ministro da Saúde); Denis Manturov (Ministro da Indústria e do Comércio); Yevgeny Ditrikh (Ministro dos Transportes); Igor Levitin (Assessor da Presidência); Chefes das Diretorias Presidenciais de Política Doméstica, de Relaçóes Públicas e Escritório de Comunicaçôes, do Serviço Federal para Supervisão da Proteção e do Bem-Estar do Consumidor (Rospotrebnadzor), do Serviço Federal para Supervisão Veterinária e Fitosanitária (Rosselkhoznadzor), da Agência Federal Médico-Biológica, do Serviço Federal Aduaneiro, do Serviço de Fronteira da FSB; e Vice-Ministros do Interior, das Relaçôes Exteriores, da Defesa, e de Emergências e Alívio de Desastres (PRESIDENT OF RUSSIA, 2020a).
(PRESIDENT OF RUSSIA, 2020b; 2020c). Após essa data, o país seguiu em quarentena até o início de junho, quando as medidas de isolamento começaram a ser flexibilizadas em Moscou, principal epicentro da crise sanitária. A partir de 14 de maio, conforme demonstrado no Gráfico 2, começou-se a observar uma diminuição no número de casos diários confirmados abaixo da média de 10.000/dia, o que incentivou o início do planejamento de movimentos para a flexibilização das medidas de controle, como o fim gradual do autoisolamento em Moscou e a reabertura gradual de fronteiras. Contudo, cabe notar um processo de interiorização do vírus, e o surgimento de novos epicentros, como as regióes do Daguestão e de Zabaikalsky, o que faz com que o relaxamento da quarentena não seja adotado de forma uniforme em todo o país (MINISTÉRIO DA SAUUDE DA FEDERAÇÃO RUSSA, 2020a).

Para refletir acerca dos impactos da pandemia na inserção regional russa, especial atenção deve ser dada às medidas de combate à pandemia COVID-19 adotadas no país. Cabe reconhecer que, logo de início, medidas de controle de circulação entre os espaços doméstico e internacional foram tomadas, com banimento à entrada de cidadãos estrangeiros, fechamento de fronteiras, e autoisolamento de pessoas vindas do exterior. Por um lado, essas açóes podem ter contribuído para o controle dos números de contaminados e de óbitos causados pelo coronavírus, mas, por outro, também acirrou os efeitos econômicos da crise, em especial com relação ao comércio com países asiáticos, como será discutido na próxima seção.

Medidas duras de circulação interna de pessoas também suscitaram ganhos no controle do vírus e polêmicas em sua implantação, como o fechamento de serviços náo essenciais, os passes digitais, o programa Moscow Safe City de câmeras de reconhecimento facial em espaços 
Tabela 1. Situação epidemiológica da COVID-19 no mundo e na Rússia

\begin{tabular}{|l|l|l|}
\hline & Mundo & Rússia \\
\hline Casos detectados & 7.446 .229 & 502.436 \\
\hline Recuperaçôes & 3.730 .356 & 261.150 \\
\hline Óbitos & 418.137 & 6.532 \\
\hline
\end{tabular}

Fonte: MINISTÉRIO DA SAÚDE DA FEDERAÇÃO RUSSA, 2020, p. 4.

Gráfico 1. Número de corsos de contominação por COVID-19 detectados na Rússia ao longo do tempo e medidas de controle tomadars pelo Estado

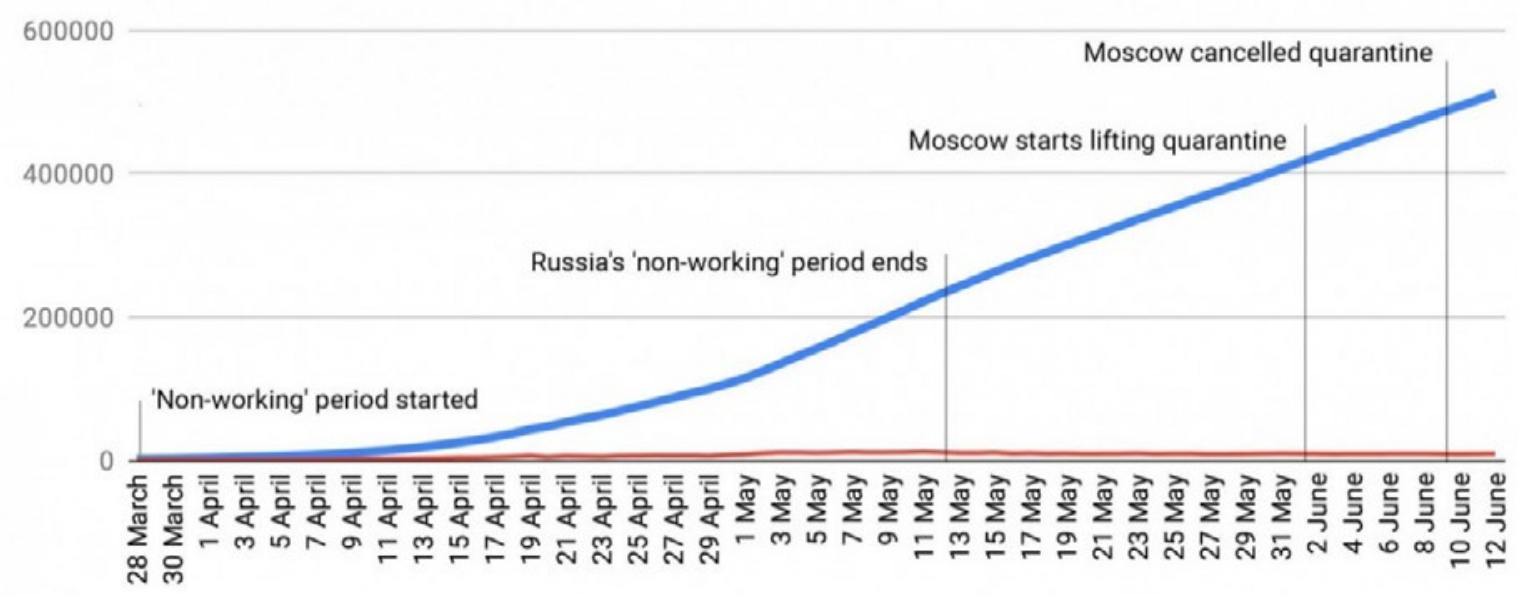

Fonte: CORONAVIRUS IN RUSSIA..., 2020 (com base nos relatórios diários do Ministério da Saúde da Federação Russa)

Gráfico 2. Número de casos de COVID-19 detectados por dia na Rússia

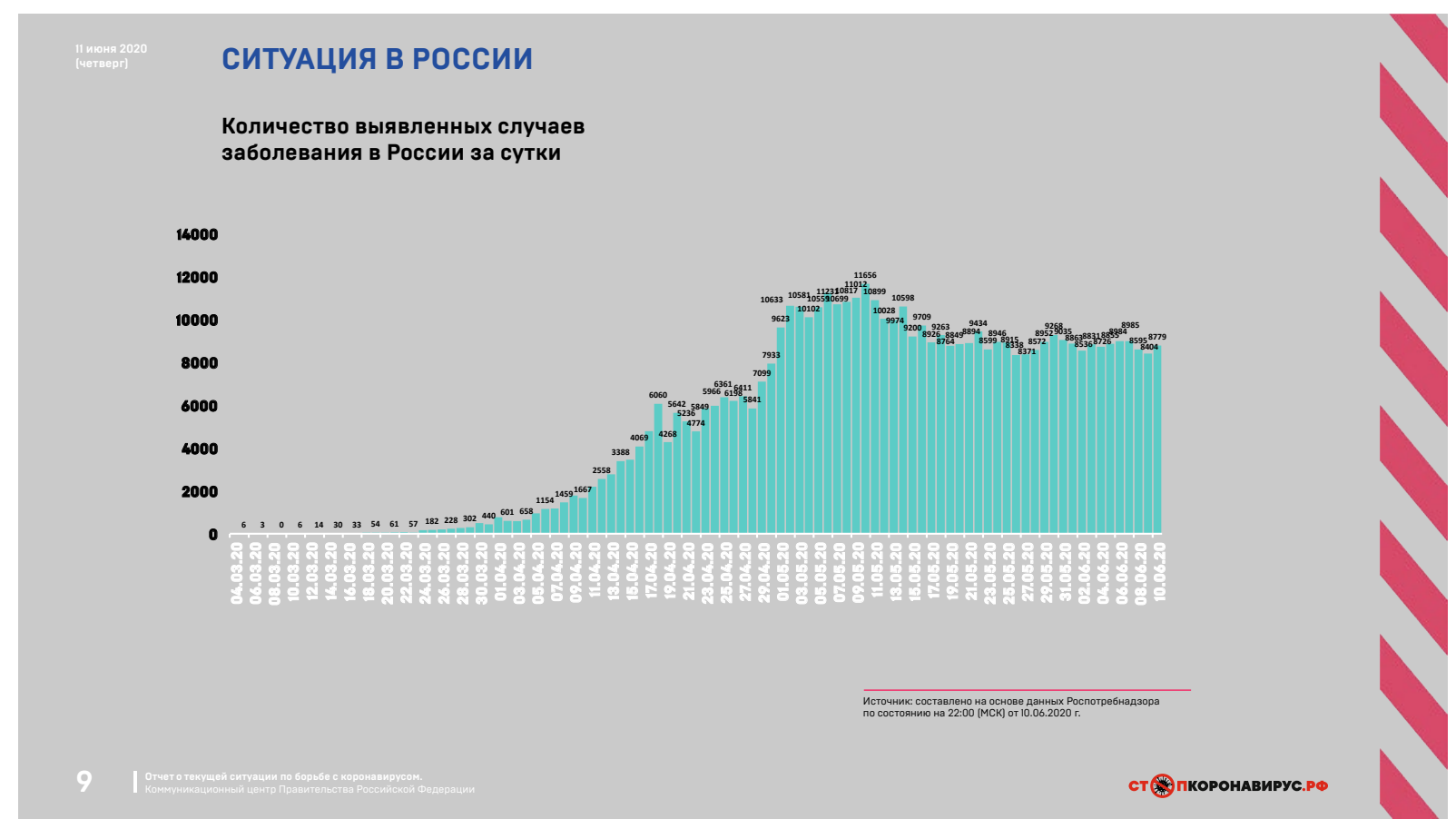

Fonte: MINISTÉRIO DA SAÚDE DA FEDERAÇÃO RUSSA, 2020a, p. 8. 
Gráfico 3. Volume da assistência social fornecida pelo governo durante a pandemia da COVID-19 até abril de 2020

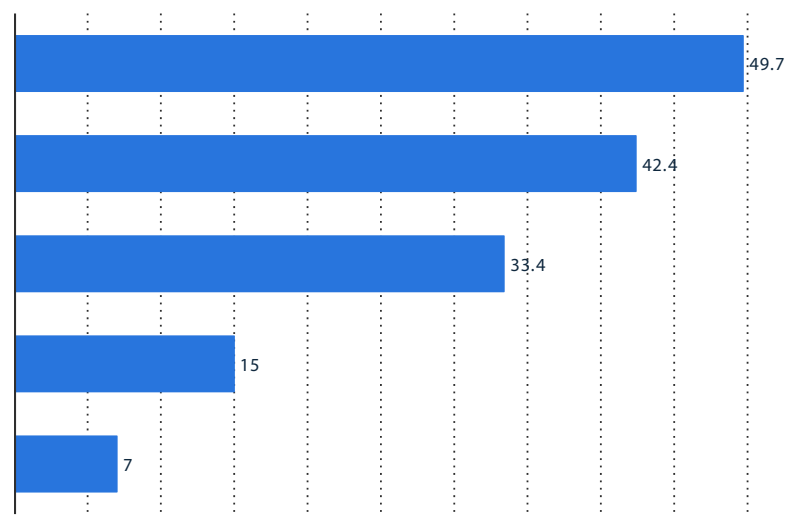

Fonte: MINISTÉRIO DO TRABALHO E DA PROTEÇÃO SOCIAL, 2020.

públicos, e o uso de drones e helicópteros por parte da Guarda Nacional Russa para controle da circulação de pessoas nas grandes cidades. Ainda, mudanças na Lei sobre Responsabilidade Administrativa por Violar Legislação que garanta Bem-Estar Sanitário e Epidemiológico da População passou a criminalizar, com pena privativa de liberdade, a divulgação de notícias falsas sobre a pandemia COVID-19, permitindo ao Kremlin forte controle das informaçôes circuladas sobre a crise sanitária (PRESIDENT OF RUSSIA, 2020f). Nesse cenário de intervençóes políticas, quatro governadores de regióes muito afetadas pela pandemia foram substituídos por decisão do governo federal (SAHUQUILLO, 2020).

A partir do dia 18 de março de 2020, uma série de medidas de assistência social foram implantadas (Gráfico 3). Anunciou-se o Plano de Recuperação Econômica de USD\$ 4 bilhôes para apoio à economia e aos cidadáos quarentenados (PRESIDENT OF RUSSIA, 2020d; 2020e). Ainda, adotou-se medidas de assistência a populaçôes específicas, como famílias com crianças, idosos, e doentes, bem como a devolução completa do imposto de renda de 2019, a redução de 6,5\% em hipotecas, assistência a pequenas e médias empresas para o pagamento de pessoal, a disponibilização de empréstimos a 2\% de juros (MINISTÉRIO DA SAÚDE DA FEDERAÇÃO RUSSA, 2020b), e o pagamento de bônus aos profissionais de saúde comprovadamente envolvidos no combate à $\mathrm{CO}$ VID-19 (PRESIDENT OF RUSSIA, 2020e). ${ }^{5}$

Ainda no que diz respeito aos investimentos russos no combate à pandemia COVID-19, observa-se grande esforço na área da pesquisa para desenvolvimento de medicamentos para tratamento e para imunização. Até o momento, quatro protótipos de vacina contra o novo coronavírus foram desenvolvidos no país, e testes em humanos já foram iniciados em maio com um desses projetos (CORONAVIRUS IN RUSSIA..., 2020). O Fundo Russo de Investimento Direto (RDIF) e atores privados russos como o Grupo Chemrar e a Yantex colaboram para o desenvolvimento de medicamentos e de testes para detecçáo da CO-

\footnotetext{
5 A concessão do benefício aos profissionais de saúde envolvidos no combate à pandemia COVID-19 na Rússia suscita polêmicas no que diz respeito aos critérios usados para que o governo comprove o envolvimento desses profissionais na crise sanitária, o que teria levado a um baixo volume de pagamento desse tipo de bônus e a críticas sobre o caráter populista da medida (BAUNOV, 2020).
} 
VID-19. Essas iniciativas apresentam grande potencial para a promoção externa da Rússia, como pode, por exemplo, ser observado em parcerias com a China, a Índia e o Japão (BOUSOV, 2020; CORONAVIRUS IN RUSSIA..., 2020; REIS, 2020). ${ }^{6}$ Com isso em mente, serão analisadas as questóes polêmicas envolvidas na evolução da pandemia na Rússia em contraposição ao cenário global, para, por fim, serem analisadas conjecturas sobre possíveis impactos políticos e econômicos da crise sanitária sobre a Rússia e sua inserção internacional na contemporaneidade.

\section{Questões polêmicas em torno da pondemia COVID-19 na Rússia}

Quando pensada em contraposição ao cenário global, a evolução da pandemia da COVID-19 na Rússia suscita três questóes especialmente polêmicas, com potencial impacto na posição de poder ocupada pelo país - as dúvidas sobre os números da pandemia, os limites para o exercício do poder vertical implantado por Vladimir Putin no governo, e os impactos econômicos sobre o desenvolvimento do país. A OMS (2020) levantou suspeitas sobre os números divulgados pelo governo russo no que diz respeito à evoluçáo da pandemia, por notar uma disparidade entre o alto número de contaminados e a baixa taxa de letalidade no país, conforme demonstrado na Tabela 2 e no Gráfico 4. Até o início de junho de 2020, a Rússia aparecia como o terceiro país do mundo com maior número de casos de contaminação pelo COVID-19 confirmado, somando um total de 510.761 casos. Em contraposição, no mesmo período, o país apresentou apenas a

\footnotetext{
6 No caso da parceria com o Japão, os russos desenvolvem pesquisas com o medicamento Avifair, que parece apresentar bons resultados como antiviral no tratamento da COVID-19 (REIS, 2020).
}

$12^{\text {a }}$ taxa mais alta de óbitos a cada mil habitantes (4,51 óbitos/1000 habitantes), segundo dados do John Hopkins Coronavirus Research Center (2020). A discrepância em comparação com as tendências mundiais levaram a críticas ao governo russo no que diz respeito aos critérios de contagem de óbitos utilizado, às denúncias de manipulação dos dados por agentes públicos, e ao alto índice de falecimentos nas equipes médicas. $\mathrm{Na}$ Rússia, os óbitos foram registrados como causados pela COVID-19 apenas em situaçóes nas quais ela representou a principal e final causa de morte, ao contrário do que é praticado na maioria dos países. Nesse cenário, as taxas de mortalidade parecem subestimadas quando comparadas com a média mensal de mortos em anos anteriores, quando foram registrados números cerca de $60 \%$ menores do que em 2020 nas grandes cidades, e cerca de $10 \%$ menores no interior. Ademais, nota-se um baixo número de testagem post mortem para verificar o diagnóstico de falecimentos suspeitos que ficam fora da contagem oficial. A ausência de dados divididos por faixa etária e gênero nos relatórios diários do Ministério da Saúde da Federação Russa, a demora em se considerar infecçóes respiratórias como possível COVID, ${ }^{7}$ e a decisão de retirar assintomáticos da contagem de contaminados ${ }^{8}$ também levam ao aumento das dúvidas sobre as estatísticas oficiais.

Ainda no que tangem às dúvidas sobre a contagem de casos na Rússia, surgiram, na mídia,

7 No dia 27 de abril de 2020, o Serviço Federal para Supervisão da Proteção e do Bem-Estar do Consumidor (Rospotrebnadzor), órgáo responsável pelos dados sobre a COVID-19, decidiu pela inclusão de infecçôes respiratórias como casos de possível contaminação pelo novo coronavírus (ROSPOTREBNADZOR, 2020).

8 No dia 27 de maio de 2020, o Rospotrebnadzor decidiu por retirar os casos assintomáticos do número de infectados pelo novo coronavírus (ROSPOTREBNADZOR, 2020). 
escândalos sobre agentes públicos promovendo a manipulação dos dados. Em 25 de maio, foi vazado um áudio de um gestor público da região de Moscou solicitando a diminuição dos óbitos registrados como causados pela COVID-19
(CORONAVIRUS IN RUSSIA..., 2020). Ainda, um em cada três médicos afirmaram ter recebido solicitaçóes de seus superiores para alteração de dados de registro sobre casos envolvendo o novo coronavírus (MEDUZA, 2020).

Tabela 2. Número total de casos de COVID-19 confirmados por país, até 12/06/2020

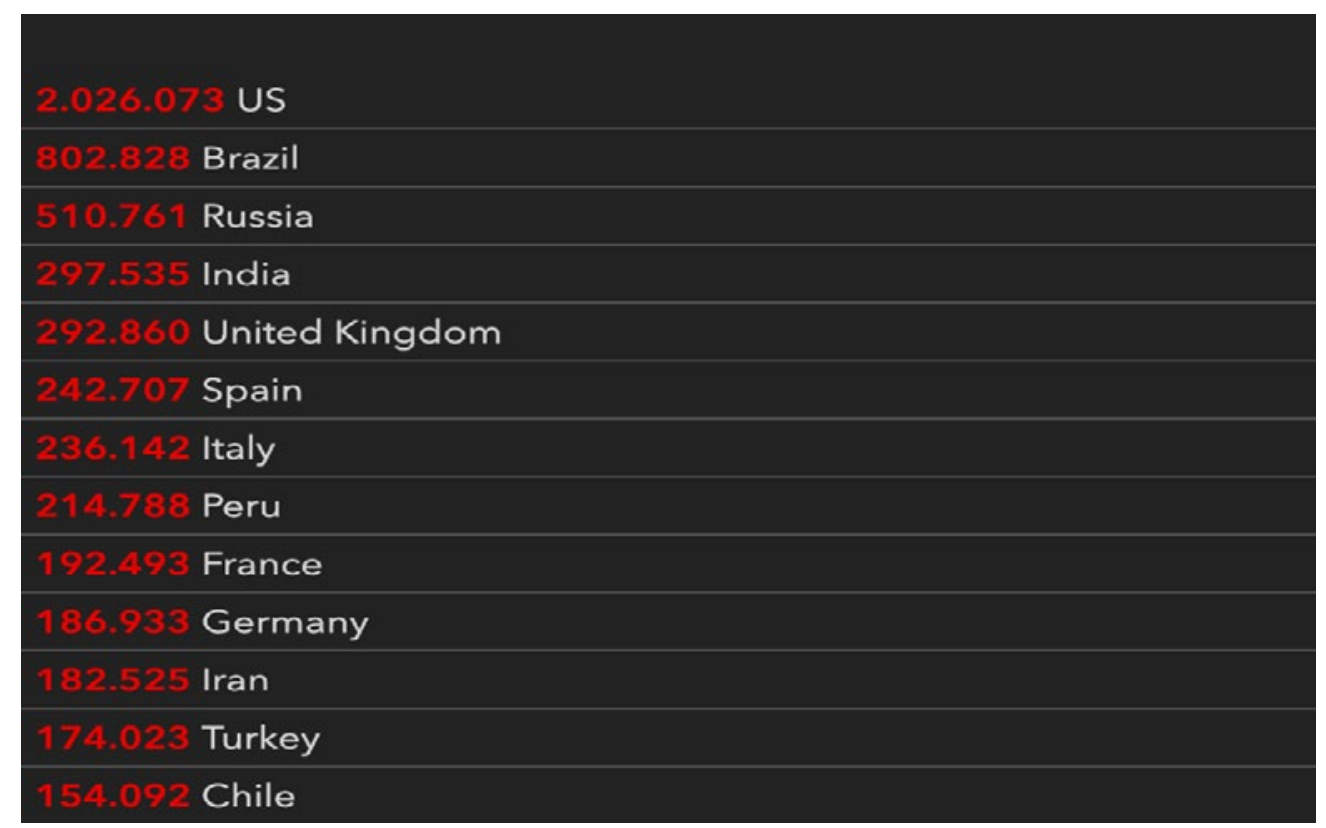

Fonte: John Hopkins Coronavirus Research Center, 12 de junho de 2020

Gráfico 4. Número de óbitos a cada mil habitantes por país, até 12/06/2020

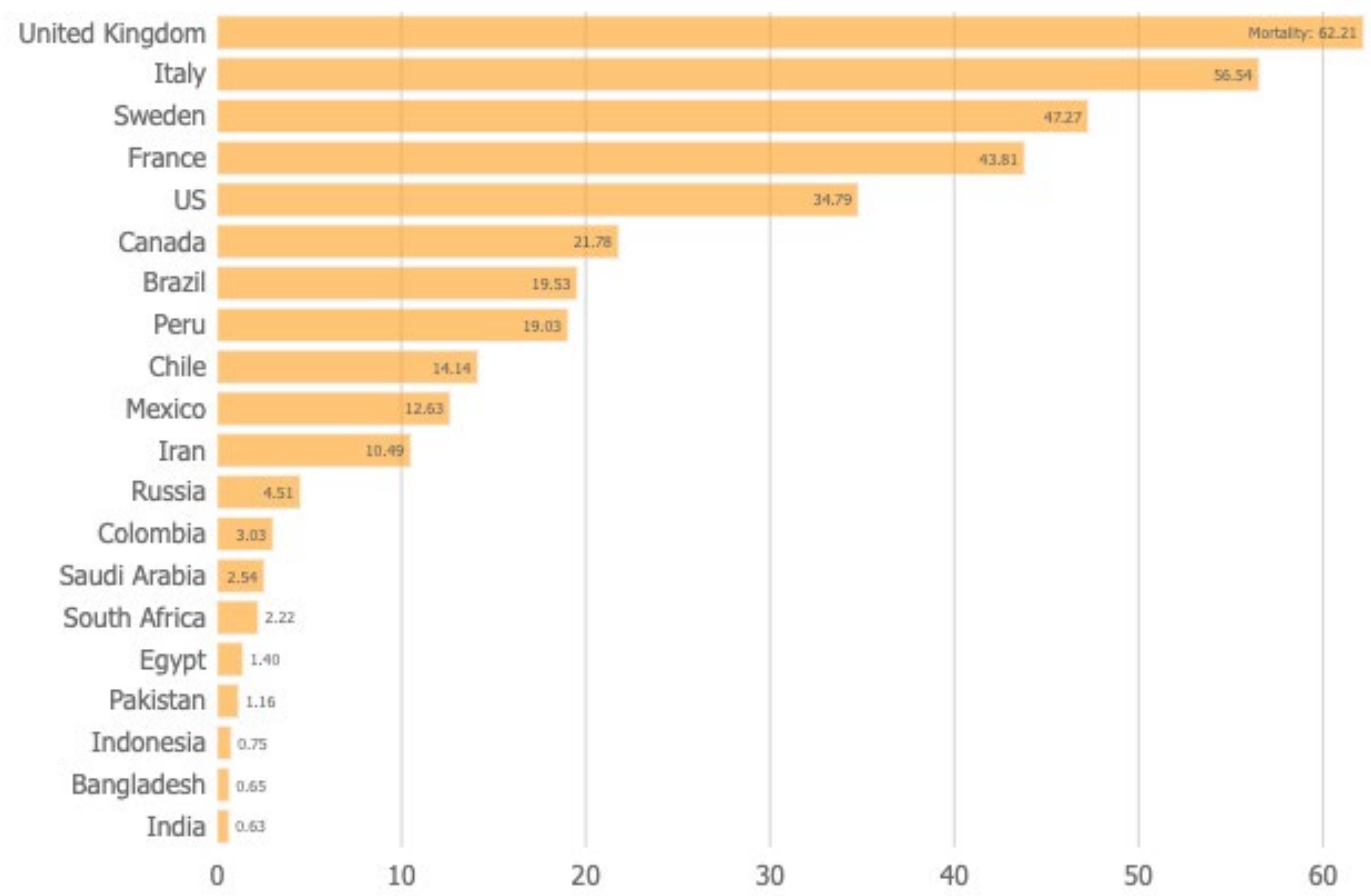

Fonte: John Hopkins Coronavirus Research Center, 12 de junho de 2020. 
Os dados oficiais sobre a taxa de letalidade por COVID-19 entre equipes médicas também são controversos, sendo que as associaçóes médicas estimam que ela seja quase o triplo na realidade, o que significaria um volume de óbitos entre membros da equipe médica cerca de dezesseis vezes maior do que em outros países com cenários semelhantes (CORONAVIRUS IN RUSSIA, 2020). Outro fator que corrobora a fragilidade dos dados é a própria revisão promovida pelo Ministério da Saúde em seus relatórios diários, que levou a dobrar a taxa de óbitos por COVID em abril e em maio nos dados oficiais (MINISTÉRIO DA SAÚDE DA FEDERAÇÃO RUSSA, 2020).

Por seu turno, o governo russo justificou a baixa taxa de óbitos na crise sanitária devido à adoção prematura e eficiente de medidas de controle de circulação de pessoas logo com a ocorrência dos primeiros casos, em fevereiro (MINISTÉRIO DA SAÚDE DA FEDERAÇÃO RUSSA, 2020); ao perfil etário mais jovem da população russa, quando compara$\mathrm{da}$ com outros países que foram epicentros da pandemia (WORLD BANK, 2020); ${ }^{9}$ à maior imunidade de rebanho; ${ }^{10}$ e ao grande índice de russos imunizados com vacina BCG. ${ }^{11} \mathrm{O}$ porta-voz do Kremlin, Dmitry Peskov, defende, ainda, a eficiência do sistema de saúde russo, que

9 A expectativa de vida na Rússia é cerca de dez anos menor do que em outros países europeus, e está em 66 anos, para mulheres, e 77 anos, para homens (WORLD BANK, 2020). Esse argumento foi defendido pelo Ministro da Saúde M. Murashko, em declaração divulgada na mídia (MOSCOW TIMES, 2020).

10 Argumento levantado pelo Gamelei Research Center de Moscou (MOSCOW TIMES, 2020).

11 Não foi ainda provada uma relação entre a imunização pela vacina BCG e a menor letalidade da COVID-19. Esse argumento foi defendido pelo Ministro da Saúde M. Murashko, em declaração divulgada na mídia (MOSCOW TIMES, 2020). seria responsável pela baixa taxa de mortalidade diante da boa atenção aos contaminados (RIA, 2020). De fato, a Rússia possui uma das mais altas taxas de respiradores por habitante. Contudo, cabe ressaltar os problemas anteriormente levantados sobre o baixo investimento e a piora nos indicadores observada ao longo do século XXI no país (OMS, 2020; ORLOVA, 2020).

A eficiência do sistema de saúde russo e a baixa taxa de letalidade em relação ao volume de contaminados foi, ainda, justificada com base nos altos índices de testagem realizada pelo governo russo (ROSPOTREBNADZOR, 2020). Medidas como distribuição gratuita de testes, parcerias com o setor privado para distribuição de testes e desenvolvimento de testes rápidos, entrega a domicílio de testes para idosos, testagem obrigatória de todas as equipes médicas, e testes aleatórios em massa, fizeram com que a Rússia esteja entre os países com maior realização de testes para COVID-19, conforme indicam o Gráfico 5 e a Tabela 3. Contudo, cabe ressaltar que a ligação do alto índice de testagem com a eficiência do sistema de saúde russo não é necessariamente direta, e que esse valor não explica o baixo volume total de óbitos.

A continuidade de Vladimir Putin no governo russo há duas décadas também pode sofrer fortes impactos da pandemia COVID-19, o que certamente influenciaria a inserção internacional do país. Desde que assumiu o Kremlin, em 2000, Putin promoveu uma série de medidas com vistas à construção de um esquema de poder vertical, pelo qual ele exerce considerável controle sobre as regiôes e sobre os demais poderes. Contudo, a dimensão teatral desse tipo de poder demonstra maior eficiência no trato de crises políticas e palcos de grande dimensão (YAFFA, 2020). 
Grófico 5. Número de testes de COVID-19 realizados na Europa até 04/06/2020, por país

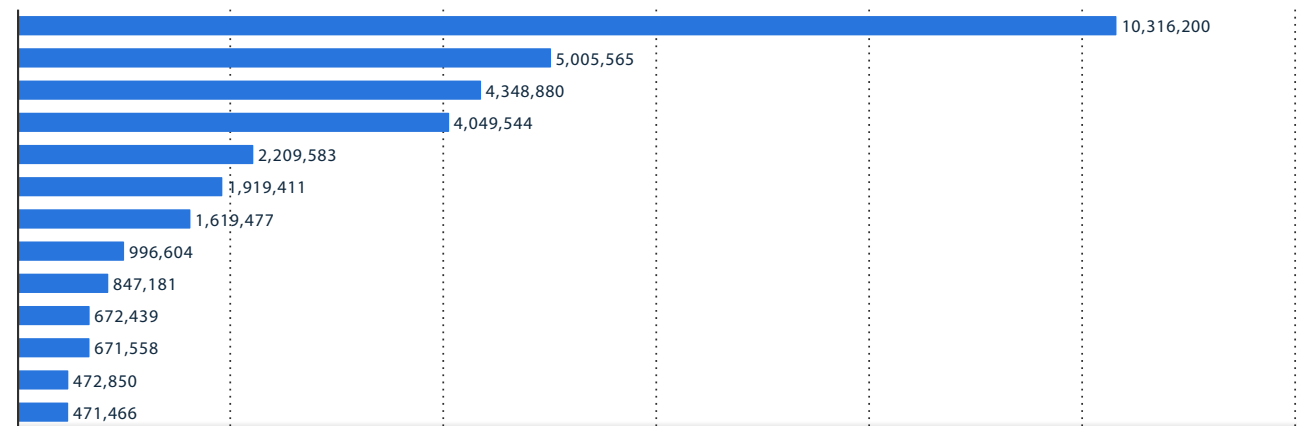

Fonte: ROBERT-KOCH INSTITUTE, 2020.

Tabela 3. Comparação do volume de testes a cada mil habitantes realizados nos três países europeus com maior volume total de testagem para COVID-19

\begin{tabular}{|l|l|}
\hline País & Média de testes por 1.000 habitantes \\
\hline Rússia em 04/06/2020 & 71,4 \\
\hline Rússia em 10/06/2020 (Fonte: Ministério da Saúde da Federaçáo Russa, 2020) & 96,07 \\
\hline Reino Unido & 75,32 \\
\hline Alemanha & 52,46 \\
\hline
\end{tabular}

Fonte: Elaborado pelas autoras, com dados da Foundation for Innovative New Diagnostics (Robert Koch-Institut), 2020; do Ministério da Saúde da Federação Russa, 2020; e do World Bank, 2020.

No caso da crise sanitária gerada pelo novo coronavírus, o grau de incerteza científica e a forte dimensão local limitam a capacidade de Vladimir Putin para mobilizar seu poder vertical em torno de sua resolução.

Diante disso, nota-se que o presidente adota uma inédita estratégia de delegação de autoridade para os níveis regional e local, parecendo buscar preservar a máxima good tsar, bad boyars. Isto é, sua abordagem para a COVID-19 envolve centrar seu discurso em torno de benfeitorias de grande vulto e de questôes geopolíticas, e repassar os custos de medidas impopulares, como o controle de circulação, a outras instâncias de poder. Essa abordagem pode ser percebida quando observados os temas mais recorrentes contidos nos atos executivos e nas declaraçóes de Vladimir Putin no período entre $1^{\circ}$ de fevereiro de 2020 e 10 de junho de 2020, conforme Gráfico 6. Especula-se se esse cenário pode indicar uma estratégia de enfraquecimento do prefeito de Moscou, Sergey So- byanin, e de blindagem do Primeiro-Ministro, Mikhail Mishustin, possível sucessor de Vladimir Putin (YAFFA, 2020).

Grófico 6. Temas recorrentes nos atos executivos publicados pelo Kremlin e nas declarações feitas por Vladimir Putin na mídia entre os dias 01/02/2020 e 10/06/2020, relacionados ò pandemia COVID-19

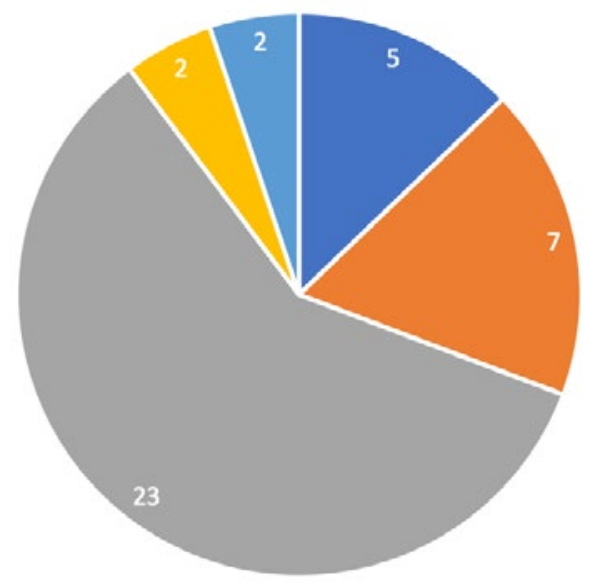

$$
\begin{array}{ll}
\text { - Geopolítica } & \text { - Assuntos domésticos } \\
\text { = Benfeitorias } & \text { = Impressão de melhora da crise } \\
\text { n Impressão de piora da crise } &
\end{array}
$$

Fonte: Elaborado pelas autoras com base em PRESIDENT OF RUSSIA, 2020; CORONAVIRUS IN RUSSIA..., 2020. 
Outra possibilidade aberta ao poder vertical envolve a implantação de instrumentos de controle instalados durante a pandemia, como os passes digitais para verificação do movimento de cidadãos via aplicativo, a instalação de postos de checagem policial, o programa Moscow Safe City de câmeras de reconhecimento facial, e as limitaçóes às aglomerações. Essas medidas podem indiretamente servir aos interesses do Kremlin sob Vladimir Putin de limitar manifestaçôes contrárias ao governo. Ainda nesse sentido, outra medida que pode ser aproveitada para esse tipo de intervenção são as emendas realizadas sobre a Lei sobre Responsabilidade Administrativa por Violar Legislação que garanta Bem-Estar Sanitário e Epidemiológico da População, em 1ํ de abril de 2020 (PRESIDENT OF RUSSIA, 2020f). A criminalização de notícias falsas sobre a epidemia do novo coronavírus levou à retirada de um artigo crítico ao governo, publicado na Novaya Gazeta, e tem sido levantada como instrumento para pressionar veículos internacionais como o Financial Times e o New York Times quando publicam na Rússia críticas à conduta do Kremlin quanto à crise sanitária (NADEAU, 2020).

Por outro lado, o poder vertical de Vladimir Putin vê-se desafiado pelo coronavírus para além de sua dificuldade acima mencionada de lidar com esse tipo de crise, a despeito da adoção da delegaçáo de poder como solução. Atualmente, Vladimir Putin enfrenta as menores taxas históricas de aprovação de seu governo - 59\% (LEVADA CENTER, 2020a). Os percentuais de aprovação e desaprovação do governo também se equilibraram nos últimos meses, sendo que a reprovação chega a ser 5\% maior do que a aprovaçáo em abril de 2020 (LEVADA CENTER, 2020a). Ainda, a percepção de que o país está na direção correta diminuiu em relação a 2019, e igualmente se apresenta equilibrada com a percepção de que a Rússia se encontra em uma direção equivocada - 42\% a 42\% (LEVADA CENTER, 2020a). Outro dado interessante sobre a percepçáo dos russos que leva ao questionamento da eficiência da estratégia de delegação são os crescentes índices de aprovação dos governos locais, que, em abril de 2020, chegaram a 61\% (LEVADA CENTER, 2020a). As medidas adotadas pelo executivo federal são, também, menos populares do que aquelas adotadas a nível regional e local, com apoio, respectivamente, de 46\% e $50 \%$ da população em abril de 2020 (LEVADA CENTER, 2020a).

$\mathrm{O}$ adiamento do referendo nacional sobre a Emenda Constitucional acerca de Melhorias na Regulação de Certos Aspectos da Organização e do Funcionamento da Autoridade Pública devido à pandemia COVID-19 também foi um duro golpe no poder vertical de Vladimir Putin. O referendo previa a consulta popular, no dia 22 de abril de 2020, que permitiria ao presidente eleger-se novamente até 2036 (PRESIDENT OF RUSSIA, 2020h), já tendo sido aprovado pela Duma e pela Corte Constitucional. Diante da impopularidade de manter um evento como esse, o Kremlin decidiu pela sua remarcação para o dia $1^{\circ}$ de julho de 2020, e modificou a legislação eleitoral para permitir voto online e por correio considerando as circunstâncias da crise sanitária (PRESIDENT OF RUSSIA, 2020i). Contudo, especula-se que essa medida possa levantar polêmicas sobre a contagem de votos mais profundas do que as verificadas em eleiçóes anteriores. Ainda assim, pesquisas de opinião pública estimam que $44 \%$ dos russos pretendem votar no referendo mesmo diante da crise sanitária, e 47\% dos cidadãos pretendem aprovar a medida (LEVADA CENTER, 2020b). 
Grófico 7. Crescimento estimado do PIB na Rússia diante de diferentes cenórios de impacto da pandemia em 2020 e em 2021

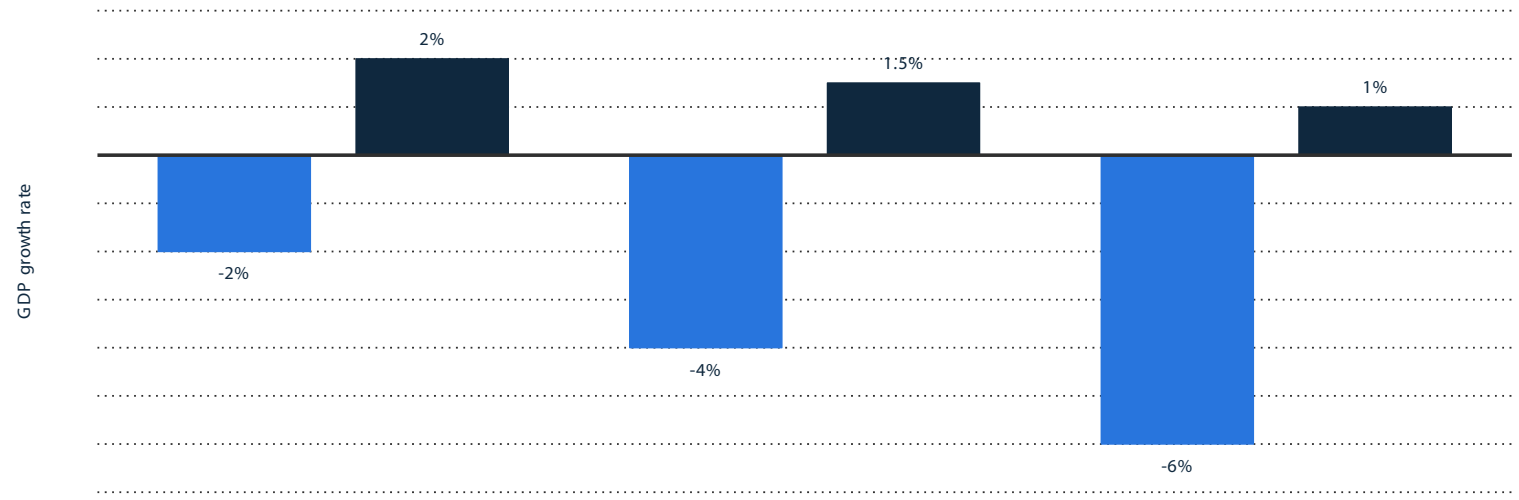

Fonte: RBC, 2020.

O adiamento das celebraçóes do Dia da Vitória para 24 de junho de 2020 também foi visto como um golpe para o poder vertical, considerando ser um momento simbólico importante de demonstração nacional e internacional do poderio russo que vem sendo fortemente articulado e incentivado por Putin nos últimos anos. ${ }^{12}$

Por fim, os impactos econômicos da crise sanitária demonstrados no Gráfico 7 deverão ser fortemente sentidos com a diminuição do preço internacional do petróleo e do gás natural e na implantação dos Projetos Nacionais propostos em 2019. A diminuição da demanda por recursos energéticos provavelmente levará a uma mudança na estratégia russa de disputa por preços com os demais produtores, como ocorrido na recente crise com a Arábia Saudita. Nesse cenário, a tendência será uma preocupação com o market share. Apesar de isso significar uma diminuição nos recursos do país, a demanda doméstica e a pequena diversificação da economia

12 O Dia da Vitória é celebrado em 9 de maio, e contaria, em 2020, com a participação de Emmanuel Macron, presidente francês, e Xi Jinping, presidente chinês, e uma forte demonstração de boas relaçôes com a Europa e com a Ásia por parte do Kremlin (ROTH, 2020). poderão equilibrar minimamente esse impacto negativo (KATONA, 2020). Por seu turno, os Projetos Nacionais em torno da ideia do Russia Big Push devem ser fortemente influenciados pelo novo coronavírus. Previa-se a instalação de um novo paradigma de desenvolvimento econômico no país por meio de um maciço investimento em infraestrutura e áreas correlatas. Contudo, a COVID-19 provavelmente levará a cortes orçamentários e à mudança de foco das açôes para abarcar intervençôes sociais e na área da saúde (LISSOVOLIK, 2020).

\section{Conclusão}

A pandemia do COVID-19 é uma calamidade internacional que atingiu todas as regióes do planeta. Assim, é importante compreender essa crise na arena internacional, mas também é preciso analisar as respostas individuais de países de grande influência regional e global, e a conjuntura na qual eles estão inseridos. A evolução da pandemia na Rússia e a gestão da crise sanitária pelo governo de Vladimir Putin vem acontecendo de forma polêmica sob a perspectiva da mídia internacional. Os efeitos da 
crise econômica subsequente à identificação do vírus no país foram percebidos desde o fechamento das fronteiras, já que o comércio com os países asiáticos caiu subitamente. Somado a isso, alguns atores internacionais e a mídia ocidental têm feito duras críticas ao governo russo sobre a sua administração da crise sanitária. Como foi discutido durante este artigo, a OMS é um órgão que levantou dúvidas importantes sobre as estatísticas divulgadas pelo governo, as consequências da crise econômica no país e os limites do poder vertical implantado por Putin.

No entanto, é necessário questionar quais impactos as denúncias feitas pela OMS ainda podem ter sobre a Rússia após o esvaziamento dessa organizaçáo, que perdeu a membresia dos Estados Unidos e, com ela, o seu financiamento. Um possível cenário futuro que pode ser consequência disso é a liderança que Putin almeja alcançar para a Rússia a partir do vácuo de poder estadunidense. O governo russo tem auxiliado com materiais e pessoal médicos outros países, o que, somado ao desenvolvimento de medicamentos e de teste de detecção do COVID-19 em alta escala, podem promover a Rússia como uma liderança internacional. Por outro lado, também é relevante considerar o possível cenário de enfraquecimento de Vladimir Putin no governo russo diante da crise sanitária e econômica. O abalo no poder vertical e nas taxas de aprovação populares de Putin já são sentidos e podem ameaçar os seus planos de reeleição.

Ainda no que tange a projeçóes futuras na arena internacional, um possível rival da Rússia na ocupação do vácuo de poder é a China, que tenta ganhar espaço na OMS por meio de maiores contribuiçóes e tenta se promover internacionalmente doando equipamentos médicos para diferentes países, assim como a Rússia. Contudo, o eixo oriental da política externa russa e a ênfase na parceria com a China podem também promover uma maior inserção internacional do país na defesa de uma ordem multilateral. Além disso, um fator agravante para Rússia que pode impedir suas aspiraçôes internacionais é o referendo programado para autorizar ou não a permanência de Putin no poder até 2036, o que é um acontecimento doméstico, mas que é extremamente criticado pelo Ocidente e tem impactos em como a Rússia é vista por outros Estados. A interpretação do público internacional sobre a atuação doméstica de Putin pode ter efeitos diretos na conquista da liderança internacional, enquanto, por outro lado, o Kremlin critica o Ocidente por usar a pandemia para desqualificar russos e chineses.

Por fim, deve-se considerar como cenário o impacto da percepção externa do governo Putin, que pode ter consequências na aceitação da vacina russa, que se encontra em estado avançado de testes. Com a crescente desconfiança da OMS e dos países ocidentais sobre a transparência do governo, todo o seu processo científico de testagem pode ser questionado e rejeitado por outros países. Diante de tantas incertezas e do aspecto multifacetado dos impactos trazidos pela pandemia, os próximos meses serão centrais para melhor compreendermos os desdobramentos desse cenário para a inserção internacional da Rússia, considerando suas respostas à crise sanitária, a posição de poder de seu presidente, e sua reação as consequências econômicas trazidas.

\section{Referências}

BAUNOV, Alexander. Where Is Russia's Strongman in the Coronavirus Crisis. Foreign Affairs, 27 maio 2020. Disponível em: https://www.foreignaffairs.com/articles/russian-federation/2020-05-27/where-russias-strongman-coronavirus-crisis. Acesso em 22 jun. 2020.

BOUSOV, Timofei. Russia and India: military and techni- 
cal cooperation in the world after COVID-19. Valdai Club, 20 maio 2020. Disponível em: https://valdaiclub.com/a/ highlights/russia-india-military-and-technical-cooperation/. Acesso em 22 jun. 2020.

JOHN HOPKINS CORONAVIRUS RESEARCH CENTER. Coronavirus Resource Center. 12 jun. 2020. Disponível em: https://coronavirus.jhu.edu. Acesso de 22 jun. 2020. KATONA, Viktor. Oil Wars 2020: who will win? Valdai Club, 6 abril 2020. Disponível em https://valdaiclub.com/a/ highlights/oil-wars-2020-who-will-win/. Acesso em 22 jun. 2020.

LEVADA CENTER. Indicators. 2020a. Disponível em: https://www.levada.ru/en/ratings/. Acesso em 22 jun. 2020.

LEVADA CENTER. Constitutional Amendments. $2020 \mathrm{~b}$. Disponível em: https://www.levada.ru/en/2020/05/28/constitutional-amendments-3/. Acesso em 22 jun. 2020.

LISSOVOLIK, Yaroslav. National Projects: Russia's New Development Paradigm. Valdai Club, 20 fev. 2020. Disponível em: https://valdaiclub.com/a/highlights/national-projects-russia-s-new-development/. Acesso em 22 jun. 2020.

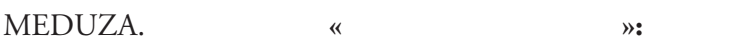

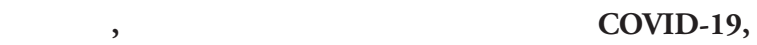

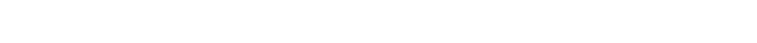
 https://meduza.io/news/2020/05/21/opros-v-spravochnike-vracha-tret-medikov-rasskazali-o-vozmozhnyh-manipulyatsiyah-so-statistikoy-covid-19?utm_source=facebook\&utm medium=main. Acesso em 10 jun. de 2020.

MINISTÉRIO DA SAÚDE DA FEDERAÇÃO RUSSA (Rozminzdrav). vid19.rosminzdrav.ru/. Acesso em 10 jun. 2020a.

MINISTÉRIO DA SAÚDE DA FEDERAÇÃO RUSSA (Rosminzdrav). Página oficial. Disponível em https://minzdrav.gov.ru/ru. Acesso em 10 jun. 2020b.

MINISTÉRIO DO TRABALHO E DA PROTEÇÃO SOCIAL. Site oficial. 2020. Disponível em: https://mintrud.gov. ru/eng. Acesso em 22 jun. 2020.

Coronavirus in Russia: the latest news. MOSCOW TIMES. Disponível em https://www.themoscowtimes. com/2020/07/01/coronavirus-in-russia-the-latest-news-july-1-a69117. Acesso em 10 jun. 2020.

NADEAU, Josh. Putin is using the pandemic to consolidate power. Foreign Policy, 18 maio 2020. Disponível em: https:// foreignpolicy.com/2020/05/18/putin-is-using-the-pandemic-to-consolidate-power/. Acesso em 22 jun. 2020.

ORGANIZAÇÃO MUNDIAL DA SAÚDE (OMS). Russian Federation. 2020a. Disponível em https://www.who.int/countries/rus/en/. Acesso em 10 jun. 2020.

ORGANIZAÇÃO MUNDIAL DA SAÚDE (OMS). WHO Press Conference. 10 de junho de 2020b. Disponível em https://www.who.int/emergencies/diseases/novel-coronavi- rus-2019. Acesso em 10 jun. 2020.

ORLOVA, Natalia. Russian National Projects during the crisis period. Valdai Club, 1 maio 2020. Disponível em: https:// valdaiclub.com/a/highlights/russian-national-projects-during-the-crisis-period/. Acesso em 22 jun. 2020.

PRESIDENT OF RUSSIA. Documents. Disponível em: http://en.kremlin.ru/acts/news. Acesso em 10 jun. 2020.

PRESIDENT OF RUSSIA. Instruction on State Council working group on coronavirus response. 15 de março de 2020a. Disponível em http://en.kremlin.ru/acts/news/62990. Acesso em 10 jun. 2020.

PRESIDENT OF RUSSIA. Address to the nation. 25 de março de 2020b. Disponível em http://en.kremlin.ru/events/ president/news/63061. Acesso em 10 jun. 2020.

PRESIDENT OF RUSSIA. Extension of measures to ensure sanitary and epidemiological safety of population in connection with the spread of the coronavirus infection. 28 de abril de 2020c. Disponível em http://en.kremlin.ru/acts/ news/63287. Acesso em 10 jun. 2020.

PRESIDENT OF RUSSIA. Executive Order on additional support measures for families with children. 7 de abril de 2020d. Disponível em: http://en.kremlin.ru/events/president/ news/63174. Acesso em 10 jun. 2020.

PRESIDENT OF RUSSIA. Amendments to Executive Order On Additional Measures of Social Support for families with children. 11 de maio de 2020e. Disponível em: http:// en.kremlin.ru/events/president/news/63342. Acesso em 10 jun. 2020.

PRESIDENT OF RUSSIA. Executive Order on providing additional insurance guarantees to individual categories of medical workers. 6 de maio de 2020f. Disponível em en.kremlin.ru/acts/news/63306. Acesso em 10 jun. 2020.

PRESIDENT OF RUSSIA. Law on administrative liability for violating legislation ensuring sanitary and epidemiological welfare of population. 1 de abril de $2020 \mathrm{~g}$. Disponível em: http://en.kremlin.ru/acts/news/63129. Acesso em 10 jun. 2020.

PRESIDENT OF RUSSIA. Law improving legislation on elections and referenduns. 23 de maio de 2020h. Disponível em en.kremlin.ru/acts/news/63387. Acesso em 10 jun. 2020.

PRESIDENT OF RUSSIA. Law on amendment to Russian Federation Constitution. 14 de março de 2020i. Disponível em: en.kremlin.ru/acts/news/62988. Acesso em 10 jun. 2020.

REIS, Fábio. Rússia aprova o avifair para tratamento da COVID-19. Pfarma, 1 jun. 2020. Disponível em: https://pfarma. com.br/coronavirus/5685-avifavir-covid19.html. Acesso em 22 jun. 2020.

RIA. पसW vel em https://ria.ru/20200611/1572799341.html. Acesso em 10 jun. 2020. 
ROBERT-KOCH INSTITUTE. Health Monitoring. Disponível em https://www.rki.de/EN/Content/Health_Monitoring/health_monitoring_node.html. Acesso em 10 jun. 2020. ROSPOTREBNADZOR. Site Oficial. 2020. Disponível em: https://www.rospotrebnadzor.ru/en/. Acesso em 22 jun. 2020. ROTH, Andrew. COVID-19 puts Putin's power plans on hold and economy in peril. The Guardian, 7 maio 2020. Disponível em: https://www.theguardian.com/world/2020/may/07/ covid-19-puts-putins-power-plans-on-hold-and-economy-in-peril. Acesso em 22 jun. 2020.

SAHUQUILLO, María R. O mistério da baixa letalidade do coronavírus na Rússia. El País, 13 maio 2020. Disponível em: https://brasil.elpais.com/sociedade/2020-05-14/o-misterio- -da-baixa-letalidade-do-coronavirus-na-russia.html. Acesso em 22 jun. 2020.

SHEIMAN, Igor; SHISHKIN, Sergey; SHEVSKY, Vladimir. The evolving Shemashko model of primary health care: the case of the Russian Federation. National Center for Biotechnology Information. Risk Management and Healthcare Policy, v. 11, p. 209-220. 2 nov. 2018. Disponível em: https:// www.ncbi.nlm.nih.gov/pmc/articles/PMC6220729/. Acesso em 18 jun. 2020.

YAFFA, Joshua. How the coronavirus revealed the hollowness of Putin vertical power. The New Yorker, 26 maio 2020. Disponível em: https://www.newyorker.com/news/dispatch/howthe-coronavirus-revealed-the-hollowness-of-putins-vertical-ofpower. Acesso em 22 jun. 2020. 